\title{
O TRABALHO INFANTIL NA CULTURA DO AÇAÍ: A NECESSIDADE DE DIÁLOGO INTERCULTURAL NA ILHA DE MARAJÓ/PA
}

\author{
Otávio Bruno da Silva Ferreira* \\ Suzy Elizabeth Cavalcante Koury**
}

Resumo: $\mathrm{O}$ artigo analisa o trabalho infantil na colheita do açaí como manifestação cultural da população ribeirinha na Ilha de Marajó. A constatação de que a subida no açaizeiro é uma das atividades mais perigosas, enquadrável como uma das piores formas de trabalho infantil, suscita o embate entre a manifestação cultural e o trabalho proibido, para cuja solução se propõe um diálogo intercultural, com envolvimento da população local, bem como a necessidade de atuação estatal no combate ao trabalho infantil. O estudo está estruturado em pesquisa qualitativa, de natureza aplicada, do tipo exploratória, com utilização de pesquisa bibliográfica e documental.

Palavras-chave: Ilha de Marajó; População Ribeirinha; Cultura; Diálogo; Trabalho Infantil.

\section{CHILD LABOR IN THE CULTURE OF AÇAÍ: THE NEED FOR INTERCULTURAL DIALOGUE ON THE MARAJÓ ISLAND/PA}

\begin{abstract}
The article analyzes the child labor in the açaí crop as a cultural manifestation of the population in the Marajó Island. The fact that the rise in the açai tree is one of the most dangerous activities, one of the worst forms of child labor, causes the clash between cultural manifestation and prohibited work, for the solution of which proposes an intercultural dialogue with the involvement of the population local level, as well as the need for state action in the fight against child labor. It's structured in qualitative research, exploratory type, with the use of bibliographical and documentary research.
\end{abstract}

Keywords: Marajó Island; Riverside Population; Culture; Dialogue; Child Labor.

\footnotetext{
* Mestrando em Direito, Políticas Públicas e Desenvolvimento Regional pelo PPGD do Centro Universitário do Estado do Pará - CESUPA. Juiz do Trabalho Substituto do Tribunal Regional do Trabalho da $8^{\text {a }}$ Região. E-mail: otavio.ferreira@trt8.jus.br

** Doutora em Direito pela Faculdade de Direito da UFMG. Desembargadora Presidente do TRT da $8^{\text {a }}$ Região. Professora dos Cursos de Graduação e de Mestrado do Centro Universitário do Pará - CESUPA. E-mail: suzykoury@gmail.com.
} 


\section{INTRODUÇÃO}

A extração do açaí, fruto da palmeira conhecida como açaizeiro (euterpe oleracea), é parte da cultura da população ribeirinha, que vem sendo transmitida de geração em geração nas várzeas, sendo realizada em toda a região estuarina ${ }^{1}$, com destaque para a Ilha de Marajó.

Essa atividade, conforme pesquisa de campo realizada pelo Instituto Peabiru (FUNDACENTRO; PEABIRU, 2016) na região do médio Rio Canaticu, no município de Curralinho, na Ilha de Marajó, Pará, com levantamento de dados no período de 2015/2016, é exercida em condições de riscos relacionados à segurança do trabalho que demandam atenção estatal e que, a despeito da importância da atividade do "peconheiro" ${ }^{2 "}$ para o desenvolvimento regional, não são consideradas pelos demais componentes da cadeia do açaí - atravessadores, comerciantes, supermercados, "batedores"3, além de serem ignorados pelo consumidor final, o que obsta a conscientização e a cobrança por medidas que garantam a sua eliminação. Diante desse cenário, o objetivo do presente estudo é analisar de que forma é possível conciliar o aspecto cultural da atividade de extração do fruto com a prática ilegal de utilização de mão de obra infantil. Para tanto, pretende-se, como objetivos específicos, descrever de que forma a cultura de extração do açaí se expressa dentro da comunidade, analisar a existência de trabalho infantil e sua regulação, bem como investigar se é possível solucionar a questão sob o prisma do diálogo intercultural.

Justifica-se a elaboração do presente estudo em face da presença marcante de mão de obra infantil e o alto grau de normalidade com que os membros da comunidade o tratam.

O estudo está estruturado da seguinte forma: a) quanto à abordagem, utilizar-se-á de pesquisa qualitativa; b) quanto à natureza, revela-se como pesquisa aplicada, com o intuito de

\footnotetext{
1 Área de água costeira semifechada com uma ligação livre com o mar aberto, sendo a transição entre um rio e um mar. É também conhecida como manguezal e sofre influência direta da ação das marés.

2 Indivíduo responsável pela extração do açaí. O nome "peconheiro" decorre da utilização da "peconha" para auxiliar na subida na árvore. A "peconha" é um instrumento em formato circular, confeccionado com o uso de folhas do açaizeiro ou com fios plásticos e sintéticos. No processo de subida, o "peconheiro" coloca a "peconha" entre os pés em formato de semicírculo, rodeando a árvore.

3 Batedores de açaí: trabalhadores responsáveis pela transformação do fruto açaí do estado natural (caroço encapado por uma massa de cor vinho escuro) em estado líquido para consumo, por meio da utilização de uma máquina conhecida como batedeira, construída sob o formato cilíndrico, colocada na forma vertical, com abertura nas duas extremidades, sendo colocada pela extremidade superior o fruto em seu estado natural, o qual é batido ao longo do cilindro, até a transformação em suco, despejado pela extremidade inferior.
} 
gerar conhecimento para aplicação prática; c) quanto aos objetivos, será do tipo exploratório e; d) quanto aos procedimentos, serão realizadas pesquisas bibliográfica e documental.

A pesquisa bibliográfica foi realizada com adoção da obra "Dignidade da pessoa humana: conteúdo, trajetórias e metodologia" de Daniel Sarmento como referencial teórico. A partir deste conhecimento, articula-se o conceito de diálogo intercultural, suas características e limitações e sua aplicação para fins de equacionamento do problema apontado neste artigo.

Importante destacar que o estudo não se esgota com a realização do presente artigo, estando em vias de realização pesquisa de campo na região para a confirmação das assertivas identificadas nas pesquisas bibliográfica e documental, bem como para a identificação de novos conhecimentos.

O texto está dividido em quatro partes. Na primeira, analisa-se a atividade de extração do açaí como demonstração da cultura de uma população tradicional. Segue-se para a análise da identificação do trabalho infantil na cadeia do açaí e, em seguida, enfrentam-se os contornos legais para caracterização do referido trabalho. Na quarta parte, analisam-se os fundamentos e os meios para a realização de diálogo intercultural como instrumento de equacionamento para o embate identificado.

O escopo do trabalho não é esgotar o tema, mas ser um instrumento inicial para o estudo de outros temas e problemas existentes na cadeira produtiva do açaí na região objeto do estudo.

\section{A EXTRAÇÃo do aÇAí COMO EXPRESSÃo CULTURAL da POPUlaÇão RIBEIRINHA}

Presente em grande parte das mesas das famílias paraenses e alimento básico para famílias ribeirinhas, o suco do fruto açaí invadiu os mercados nacional e internacional, estando na iminência de se tornar uma commodity.

Contudo, pouco se sabe e se discute sobre o início da cadeia produtiva do fruto. Afinal, o produto não é transplantado de um açaizeiro localizado no meio da floresta para o supermercado sem a intervenção de um ator social de suma importância: o peconheiro. É ele que utiliza uma embarcação, adentra a floresta, coloca a peconha no pé, sobe no açaizeiro com uma faca presa à cintura e se dedica a escalar metros e metros de palmeira para apanhar o cacho 
do fruto. Em seguida, com vários cachos nas mãos, controla o movimento de descida apenas com as pernas e os pés. Por vezes, salta de uma árvore para outra para pegar outros cachos de fruto.

Esse roteiro quase romântico não ocorre com a tranquilidade que a descrição parece lhe atribuir. É que, não raro, o peconheiro sofre escoriações no corpo, a exemplo de perfuração em suas costas pela faca que carrega, escorrega ou cai da árvore, acarretando a quebra de algum membro, é picado por insetos, além de outras situações perigosas.

A despeito da situação acima narrada e da importância da cadeia do açaí para o desenvolvimento econômico e social da região, inexiste preocupação estatal e regramentos que garantam a segurança e a proteção do peconheiro. A preocupação atual limita-se ao momento que o produto já foi retirado da árvore e está pronto para o consumo, com clara invisibilidade do elo primeiro da cadeia produtiva.

Em pesquisa realizada pelo Instituto Peabiru, no período de março de 2015 a maio de 2016, com entrevistas, observações, levantamentos bibliográficos e estudos de campo realizados no médio Rio Canaticu, município de Curralinho, na Ilha do Marajó, Pará, área na qual há diversas famílias que exploram a atividade, foram identificadas, dentre outras, as seguintes ocorrências:

- $\quad$ A condição de trabalho na atividade extrativista da cadeia de valor do açaí nunca havia sido tratada com tal amplitude e profundidade como no presente estudo;

- $\quad$ A FUNDACENTRO e Instituto Peabiru observam que a atividade é uma das mais perigosas do Brasil;

- $\quad$ O que mais chama a atenção é o grau de precariedade da atividade;

- $\quad$ A questão do trabalho infantil não foi objeto do trabalho, mas mostrou-se presente no ambiente, necessitando ser estudada na cadeia de valor do açaí, pois numa atividade tradicional, o mais ágil, leve e ousado, sobe rapidamente e colhe o necessário para o consumo diário da família. E, diante de um mercado crescente, quem antes subia diariamente uma ou duas vezes no açaizeiro, agora sobe dez ou mais vezes e, ainda, pula, de uma árvore a outra;

- $\quad$ Os riscos se multiplicam se considerarmos que, num dia de pico de safra há algo próximo de 1 milhão de subidas em açaizeiros;

- Uma atividade típica da agricultura familiar se tornou uma cadeia de valor global, com características de uma commoditie, abrangendo um número estimado de mais de 120 mil famílias, envolvendo de 2 a 4 trabalhadores por família;

- $\quad$ A longo prazo, especialmente para jovens, o esforço físico de subir na árvore, resultará em consequências permanentes para suas vidas, especialmente afetando os pés e as pernas; (PEABIRU, FUNDACENTRO, 2016)

Do resultado acima, constatam-se três problemáticas: a) a precariedade do modo de 
extração do açaí; b) a existência de trabalho infanto-juvenil e c) a inexistência de responsabilidade dos demais integrantes da cadeia produtiva. Todas elas merecem estudo aprofundado e reflexões, tanto pela academia, quanto pela sociedade. Este estudo limitar-se-á à análise do trabalho infantil na extração do açaí.

Marinho (2005), em pesquisa realizadas no rio médio Pracuúba, no município de São Sebastião da Boa Vista, também localizado na Ilha de Marajó, identificou que:

a utilização da mão-de-obra infantil nos açaizais é tão comum que ninguém condena esta prática. Ao invés disto, é até motivo de orgulho para um pai afirmar que seu filho, de 8 anos de idade, já é capaz de apanhar 3 ou 4 latas de açaí por dia. Isto, que para os olhos de alguém de fora configura, no mínimo, um típico caso de exploração do trabalho infantil, para a população ribeirinha não passa de um fato corriqueiro, tão natural que difícil é encontrar alguma criança, a partir dos 8 anos que não saiba "subir na açaizeira", como se diz localmente.

O fato de a atividade de extração do açaí realizada por crianças e adolescentes ser vista de forma natural revela o quão tradicional a atividade é para a população ribeirinha, fazendo parte de sua cultura.

Para Sarmento (2016, p. 278), “a cultura é essencial para a vida das pessoas” pois é por meio dela que se reconhecem como parte de um grupo e afirmam sua identidade enquanto pessoas. Afinal, o indivíduo necessita, para a construir a sua identidade, do reconhecimento pelo outro, de modo que a formação cultural do indivíduo está intrinsecamente relacionada à sua participação do grupo. Daí porque o grau de justiça e injustiça varia de acordo com aquilo que o grupo entende como justo ou não.

Nesse contexto, Sarmento (2016, p. 278) frisa que

a cultura fornece um contexto de escolha para os indivíduos. Isso não quer dizer que as culturas sejam estáticas, nem que os indivíduos não passem de membros de uma coletividade cultural, mas, sim, que os valores compartilhados, modos de vida e tradição são fatores importantíssimos para a identidade de cada um.

Especificamente a respeito das populações tradicionais, a exemplo de indígenas, quilombolas e, no caso em estudo, da população ribeirinha, os valores compartilhados pela comunidades tendem a assumir um peso maior na formação da identidade das pessoas integrantes do grupo.

Nesse contexto, identifica-se que a subida no açaizeiro é prática cultural da população ribeirinha, passada de geração em geração, com o reconhecimento daquele que consegue subir 
na árvore e que é motivo de orgulho para os seus familiares.

Nota-se que a comunidade compartilha dos mesmo valores, como expressão imaterial de sua cultura, sem preocupação com o aspecto ilícito do trabalho infantil.

\section{O TRABALHO INFANTIL DA EXTRAÇÃO DO AÇAÍ}

Segundo Marinho (2005), a extração do açaí é uma atividade que envolve homens, mulheres e crianças, sem uma rígida divisão do trabalho, pois todos os extratores envolvidos, independentemente de idade e gênero, podem se dedicar a qualquer etapa do processo extrativo, ainda que, na área estudada, tenha se observado que as mulheres se dediquem mais à debulha ${ }^{4}$, enquanto os homens e as crianças se ocupam, preferencialmente, com a extração propriamente dita.

Identifica-se, portanto, “a exposição de dezenas de milhares de jovens (número que precisa ser melhor avaliado pelos órgãos competentes), muitos sem idade para trabalhar, tanto homens, como mulheres, a uma atividade profissional que exige grande esforço e é de alto risco" (PEABIRU, 2016).

Segundo PEABIRU (2016):

o jovem, que é mais ágil, mais leve, ousado e mais corajoso, sobe 8 rapidamente em uma ou poucas árvores de açaí e colhe o necessário para o consumo diário da família. Entretanto, na última década, com o crescimento exponencial da demanda pelo vinho (polpa) de açaí, a coleta passou a atender, não apenas o consumo da própria família ou localidade, ou o limitado mercado regional, que consume o açaí fresco, in natura, para se transformar em uma cadeia de valor de interesse global, envolvendo novos elos de cadeia de valor (indústrias processadoras, atacadistas, varejistas e outros.

Para a extração do açaí, o peconheiro, pessoa responsável pela subida na árvore, utiliza peconha e terçado, subindo, geralmente, sem camisa e sem proteção no terçado para evitar perfuração ou arranhão. Nota-se que a atividade é uma das mais perigosas do Brasil (PEABIRU, FUNDACENTRO, 2016).

Segundo Marinho (2005), a distribuição de atividades é definida, em linhas gerais, de acordo com o sexo e a idade de cada membro do grupo, o que não significa um rígido seccionamento de funções entre o chefe da família, as crianças (geralmente meninos) e a

4 Processo de extração do fruto açaí do cacho. Normalmente realizado com o uso das mãos. 
esposa, ainda que esta, em geral, desempenhe as atividades consideradas menos pesadas no açaizal, mas, por outro lado, execute os serviços domésticos praticamente sozinha.

Continua afirmando, que nas grandes propriedades, há extrator que consegue coletar, com a ajuda dos filhos e da esposa, até 50 latas de açaí por dia. Já nos açaizais menores, esta quantia pode baixar para 25 a 30 latas, por dia (até o meio dia). As subidas ocorrem, geralmente, pela parte da manhã, em virtude da necessidade de vender o produto ainda durante o dia e evitar a redução de sua qualidade por se tratar de alimento perecível.

A respeito do trabalho de crianças na cadeia do açaí, Peabiru (2016), na pesquisa realizada no rio médio Canaticu, na Ilha de Marajó, enfatizou que

A questão do trabalho infantil não foi objeto do trabalho, mas mostrou-se presente no ambiente, necessitando ser estudada na cadeia de valor do açaí, pois numa atividade tradicional, o mais ágil, leve e ousado, sobe rapidamente e colhe o necessário para o consumo diário da família. E, diante de um mercado crescente, quem antes subia diariamente uma ou duas vezes no açaizeiro, agora sobe dez ou mais vezes e, ainda, pula, de uma árvore a outra"

Da mesma forma, na pesquisa realizada no rio médio Pracuúba, também na Ilha de Marajó, Marinho (2005), identificou que

Estas [crianças], sobretudo do sexo masculino, são iniciadas precocemente na extração do açaí. $O$ processo de aprendizagem em geral começa aos 6, 7 anos de idade. Nesta ocasião, os meninos começam a dar seus primeiros saltos naqueles açaizeiros baixinhos, normalmente com o incentivo do pai, que lhe dá algumas instruções elementares, como ter cuidado para a peconha não sair dos pés e os braços não escaparem do fino caule da palmeira. Com isto, a partir de 8, 9 anos de idade, um pouco mais fortes fisicamente, essas crianças já são ágeis coletoras, com habilidade e coragem invejáveis. Além dessas qualidades, um outro aspecto que atribui importância central à mão-de-obra infantil é o reduzido peso das crianças. Esta característica permite a elas escalarem praticamente qualquer palmeira, inclusive aquelas que os adultos não conseguem porque são mais pesados. Deste modo, percebe-se que, embora não tenham a mesma resistência de um extrator experiente, as crianças, em certas ocasiões, mostram-se mais eficientes, ainda que expostas a maiores riscos, porque dificilmente voltam de uma palmeira antes de extrair seu fruto. Por esta importância, não se verifica localmente nenhuma preocupação relativa às implicações que o massivo uso da mão-de-obra infantil pode acarretar para o crescimento das crianças.

Identifica-se, portanto, a exploração de mão de obra infantil na cadeia produtiva do açaí sem a preocupação com o possível retardo e prejuízo do desenvolvimento físico e intelectual da criança e sem a devida observância de sua condição peculiar de pessoa em desenvolvimento.

Na Amostra Trabalho Infantil (BRASIL, 2010) do Instituto Brasileiro de Geografia e 
Estatísticas - IBGE, no município de São Sebastião da Boa Vista, identificou-se o percentual de 14,8\% de pessoas de 10 a 17 anos ocupadas na semana de referência.

Na faixa etária de 10 a 13 anos, o nível de ocupação é de 8,9\%, com proporção idêntica para os sexos masculino e feminino, sendo $7 \%$ na zona urbana e 10,2\%, na zona rural. Na faixa etária de 14 ou 15 anos, o nível de ocupação é de 14,3\%, sendo 15,7\% para pessoas do sexo masculino e $12,7 \%$ para pessoas do sexo feminino, sendo $11,4 \%$ na zona urbana e $15,8 \%$ na zona rural. E, por fim, na faixa etária de 15 ou 16 anos, o nível de ocupação é de 26,7\%, sendo $38,4 \%$ para pessoas do sexo masculino e $16 \%$ para pessoas do sexo feminino, sendo $26,1 \%$, na zona urbana e $27,2 \%$, na zona rural.

Nos grupos de idade foram identificadas 2.277 pessoas na faixa etária de 10 a 13 anos, 1.207 na faixa etária de 14 ou 15 anos e 1.176 na faixa etária de 16 ou 17 anos, o que permite concluir, proporcionalmente, pela existência de um número considerável de crianças que trabalham.

No geral, o percentual de taxa de ocupação na zona urbana é de 13,4\% e na zona rural, de $15,7 \%$. Além disso, para pessoas do sexo masculino o percentual é de $54,4 \%$ e para pessoas do sexo feminino de $31,5 \%$.

Sobre a situação domiciliar, 1.865 residiam na zona urbana e 2.795 residiam na zona rural.

No universo de 4.660 pessoas de 10 a 17 anos de idade, 4.273 são alfabetizadas e 387 não o são. De outro lado, 719 não frequentavam a escola, sendo que 212 residiam na zona urbana e 508 na zona rural.

A respeito da ocupação e das atividades desenvolvidas pelas pessoas de grupo etário de 10 a 17 anos, identificou-se que 52,3\% estavam ocupadas em atividades de agricultura, pecuária, produção florestal, pesca e aquicultura, sendo 50,5\%, na faixa etária de 10 a 13 anos, 65,8\%, na faixa etária de 14 ou 15 anos e 46,1\%, na faixa etária de 16 ou 17 anos, exclusive as empregadas com carteira de trabalho assinada; 20,7\% estavam ocupadas na atividade de comércio, reparação de veículos automotores e motocicletas, sendo 19,9\%, na faixa etária de 10 a 13 anos, 21\%, na faixa etária de 14 ou 15 anos e 21\%, na faixa etária de 16 ou 17 anos, exclusive as empregadas com carteira de trabalho assinada; e 21,9\% estavam envolvidas em outras atividades. 
Sobre a taxa de analfabetismo, o percentual para pessoas de 10 a 17 anos é de 8,3\%, com maior incidência no grupo etário de 10 a 13 anos, 11,6\%, sendo que 3,8\% das pessoas estavam ocupadas e $12,4 \%$ não eram ocupadas.

Dos dados acima, é possível compreender a existência de trabalho infantil no município de São Sebastião da Boa Vista em número bastante considerável e que tal amostra está, em grande parte, atuando na zona rural em atividade relacionadas à agricultura, são do sexo masculino e que, da amostra que não frequentava a escola, a maior parte também reside na zona rural.

A pesquisa feita pelo IBGE retrata a consequência de utilização da mão de obra infantil em atividade perigosa e contínua. Nota-se que, em face de tal atuação, um efeito marcante no número de crianças ocupadas na zona rural que deixam de frequentar a escola, o que revela o descompromisso com o direito fundamental à educação e o dever de cuidar adequadamente da criança, pondo-lhe a salvo de toda e qualquer situação de perigo.

\section{DA CARACTERIZAÇÃO LEGAL DO TRABALHO INFANTIL NA CADEIA DO AÇAÍ}

A respeito dos marcos normativos, a Constituição da República Federativa do Brasil de 1988 (BRASIL, 1988), elenca com um de seus fundamentos a dignidade da pessoa humana (art. $\left.1^{\mathrm{o}}, \mathrm{III}\right)$, e como objetivos fundamentais (art. $\left.3^{\circ}\right)$ :

construir uma sociedade livre, justa e solidária; garantir o desenvolvimento nacional; erradicar a pobreza e a marginalização e reduzir as desigualdades sociais e regionais e promover o bem de todos, sem preconceitos de origem, raça, sexo, cor, idade e quaisquer outras formas de discriminação.

Prevê ainda, em seu art. $7^{\circ}$, que "são direitos dos trabalhadores urbanos e rurais, além de outros que visem à melhoria de sua condição social":

XXII - a redução dos riscos inerentes ao trabalho, por meio de normas de saúde, higiene e segurança";

XXXIII - a proibição de trabalho noturno, perigoso ou insalubre a menores de dezoito e de qualquer trabalho a menores de dezesseis anos, salvo na condição de aprendiz, a partir de quatorze anos.

Aprofundando a proteção à criança e ao adolescente, dispõe, em seu art. 227, que: 
É dever da família, da sociedade e do Estado assegurar à criança, ao adolescente e ao jovem, com absoluta prioridade, o direito à vida, à saúde, à alimentação, à educação, ao lazer, à profissionalização, à cultura, à dignidade, ao respeito, à liberdade e à convivência familiar e comunitária, além de colocá-los a salvo de toda forma de negligência, discriminação, exploração, violência, crueldade e opressão.

No âmbito internacional, a Convenção $\mathrm{n}^{\mathrm{o}}$. 182 da Organização Internacional do Trabalho (OIT, 1999), que versa sobre a Proibição das Piores Formas de Trabalho Infantil e a Ação Imediata para a sua Eliminação, promulgada pelo Decreto $\mathrm{n}^{\circ} .3 .597$, de 12 de setembro de 2000, dispõe que "a expressão 'as piores formas de trabalho infantil' abrange”: [...] “d) o trabalho que, por sua natureza ou pelas condições em que é realizado, é suscetível de prejudicar a saúde, a segurança ou a moral das crianças."

No artigo 4, articula que:

Os tipos de trabalhos a que se refere o Artigo 3, d), deverão ser determinados pela legislação nacional ou pela autoridade competente, após consulta às organizações de empregadores e de trabalhadores interessadas e levando em consideração as normas internacionais na matéria, em particular os parágrafos 3 e 4 da Recomendação sobre as piores formas de trabalho infantil.

De outro lado, a Recomendação 190 (OIT, 1999), que dispõe sobre a Proibição das Piores Formas de Trabalho Infantil e a Ação Imediata para a sua Eliminação, disciplina o assunto da seguinte forma:

\section{Trabalho perigoso}

1. Ao determinar e localizar onde se praticam os tipos de trabalho a que se refere o artigo 3, d) da Convenção, deveriam ser levadas em consideração, entre outras coisas:

a) os trabalhos em que a criança ficar exposta a abusos de ordem física, psicológica ou sexual;

b) os trabalhos subterrâneos, debaixo d'água, em alturas perigosas ou em locais confinados;

c) os trabalhos que se realizam com máquinas, equipamentos e ferramentas perigosos, ou que impliquem a manipulação ou transporte manual de cargas pesadas;

d) os trabalhos realizados em um meio insalubre, no qual as crianças estiverem expostas, por exemplo, a substâncias, agentes ou processos perigosos ou a temperaturas, níveis de ruído ou de vibrações prejudiciais á saúde, e

e) os trabalhos que sejam executados em condições especialmente difíceis, como os horários prolongados ou noturnos, ou trabalhos que retenham injustificadamente a criança em locais do empregador.

Pelo teor acima, identifica-se que a atividade de retirar o fruto do açaizeiro é uma das piores formas de trabalho infantil por ser realizada em alturas perigosas, com ferramentas 
perigosas, em meio ambiente insalubre e em condições especialmente difíceis. Em cumprimento à Convenção e à Recomendação acima, no plano interno, o Decreto $\mathrm{n}^{\circ}$. 6.481, de 12 de junho de 2008 (BRASIL, 2008), regulamentou os artigos 3므, alínea “d”, e 4- da Convenção 182 da Organização Internacional do Trabalho (OIT), elencando a Lista das Piores Formas de Trabalho Infantil, conhecida Lista TIP.

$\mathrm{Na}$ referida Lista, a despeito de não constar expressamente a atividade de peconheiro, há um elenco de prováveis riscos ocupacionais e prováveis repercussões à saúde decorrente de atividades que se enquadram em diversas ocupações.

É tida como uma das piores formas de trabalho infantil trabalhar "Com utilização de instrumentos ou ferramentas perfurocontantes, sem proteção adequada capaz de controlar o risco", tendo sido apresentado como prováveis riscos ocupacionais "Perfurações e cortes" e prováveis repercussões à saúde os "Ferimentos e mutilações".

Também está elencada dentre aquelas atividades, trabalhar "ao ar livre, sem proteção adequada contra exposição à radiação solar, chuva , frio", com prováveis riscos ocupacionais a "Exposição, sem proteção adequada, à radiação solar, chuva e frio" e como prováveis repercussões à saúde "Intermações; queimaduras na pele; envelhecimento precoce; câncer de pele; desidratação; doenças respiratórias; ceratoses actínicas; hipertemia; dermatoses; dermatites; conjuntivite; queratite; pneumonite; fadiga; intermação".

Consta, ainda, como atividade perigosa trabalhar "em alturas superiores a 2,0 (dois) metros", tendo como prováveis riscos ocupacionais "Queda de nível” e como prováveis repercussões à saúde "Fraturas; contusões; traumatismos; tonturas; fobias".

Nesse contexto, identifica-se o enquadramento da atividade do peconheiro dentre as piores formas de trabalho infantil, sendo importante, inclusive, para garantir a visibilidade do problema, a inclusão da referida atividade no elenco daquela lista. Necessário destacar que, para os efeitos da Convenção nº 182 (OIT, 1999), art. 2, o termo "criança" designa toda pessoa menor de 18 anos. Daí porque o tratamento das piores formas de trabalho infantil abrange o trabalho da criança e do adolescente no Brasil.

De todo esse arcabouço normativo, denota-se que a positivação dos direitos da criança, inclusive no texto constitucional, fundada na doutrina da proteção integral, demonstra o compromisso do Estado em garantir o pleno exercício de seus direitos, com observância da 
característica especial de pessoa em desenvolvimento, pondo-lhe a salvo de toda e qualquer forma, ambiente ou situação que possam prejudicar seu crescimento físico e intelectual, bem como prejudicar sua moral.

Não é suficiente o interesse da academia e dos centros de pesquisa sobre as questões e o impacto da atuação nestas cadeias de valor na saúde humana e qualidade de vida destes trabalhadores e familiares (PEABIRU, 2016).

A precariedade em que se encontra o extrativista, o elo mais frágil da cadeia (POTIGUAR; OLIVEIRA, 2016), é clara demonstração de escassez de políticas públicas e da consequente falta de relações formais de produção nos elos em ele atua.

A respeito do alcance da população atingida pela ausência de política pública efetiva, “acredita-se, de qualquer maneira, que o Pará e o Amapá juntos, especialmente na região esturiana [sic] (Marajó, Amapá e Baixo Tocantins), representem mais de 80\% da coleta do açaí nativo" (PEABIRU, 2016).

É preciso também diferenciar a realização de extrativismo para consumo familiar da produção em cadeia. É que a atividade extrativista, realizada inicialmente para o consumo próprio, tomou proporções mercadológicas exigindo o aumento da produção e, por consequência, interferindo no aumento de subidas e descidas no açaizeiro (Euterpe olereacea), com aumento da exposição a riscos e acidentes.

A atividade de subir no açaizeiro sempre fez parte da cultura tradicional do povo amazônico, com início de aprendizagem desde cedo e com ensinamentos passados de geração em geração.

A insegurança na atividade do peconheiro é ocultada na cadeia produtiva, a ponto de não refletir no preço do produto. Além disso, a ocorrência de acidentes é tamanha que " $89 \%$ dos entrevistados disseram que alguém de sua família ou meeiro já sofreu um acidade de trabalho em seu açaizal". (PEABIRU, 2016).

Nota-se, portanto, a caracterização do trabalho infantil na cadeia produtiva do açaí, o qual, como analisado, é proibido em virtude das consequências lesivas que provoca no desenvolvimento físico e mental da criança, bem como por representar violação aos seus direitos básicos, a exemplo do lazer, da educação e de observar a sua característica de pessoa em desenvolvimento. 
De outro lado, como visto na primeira parte, a atividade é tratada pela comunidade como cultural, transmitida de geração em geração, sem a preocupação devida.

Nesse contexto, é relevante analisar como e quais os instrumentos podem ser utilizados para compreender a situação e propor melhorias dialogadas que compatibilizem o respeito à criança e à cultura da população ribeirinha.

\section{O DIÁlOGO INTERCULTURAL COMO INSTRUMENTO PARA O COMBATE DO TRABALHO INFANTIL NA CADEIA DO AÇAÍ}

A partir dos argumentos até agora apresentados, pode-se identificar o seguinte embate: de um lado, a ocorrência de violação às normas que proíbem o trabalho infantil. De outro, há a manifestação cultural de uma comunidade tradicional no tocante ao desenvolvimento de sua atividade econômica. Nesse contexto, revela-se importante o cumprimento daquelas regras sem que isso possa impactar na reprodução social e material dos povos.

Assim, surge como premissa necessária compreender como caracterizar e reconhecer o trabalho infantil na cadeia produtiva do açaí, com a necessária distinção da sua extração como impulsionada pelo mercado daquela primitiva, exercida dentro da agricultura familiar. Tais compreensões devem fazer parte do conhecimento das famílias tradicionais, pois são eles os responsáveis pela mudança de atitude.

O embate entre os dois pontos citados atrai a possibilidade de utilização do diálogo intercultural. Para Sarmento (2016, p. 291),

O diálogo intercultural parte da premissa de que existem nas culturas diferentes correntes interpretativas, algumas mais favoráveis à emancipação do que outras. Explorar as vertentes culturais progressistas é uma estratégia mais produtiva para a defesa da dignidade da pessoa humana em contextos não ocidentais por conferir maior legitimidade social aos direitos, ampliando as chances de que conquistem a adesão genuína das pessoas.

É importante assinalar que o diálogo intercultural não serve apenas para resolver problemas jurídicos e morais. Ao lado disso, é fonte de aprendizado para a sociedade envolvente, que lhe permite ter contato com valores e experiências alternativas, que podem, eventualmente, revelar a incompletude de suas práticas sobre direitos humanos. A abertura ao diálogo permite a ampliação dos horizontes e do próprio repertório de condutas da comunidade, 
daí porque sua realização permite que a sociedade se conheça melhor, com a provocação de reflexos sobre seus próprios problemas e a geração de soluções pautadas em novos conhecimentos e novos olhares.

Identifica-se que o diálogo intercultural não visa à eliminação de determinada cultura por outra hegemônica. Ao contrário, o diálogo serve para o reconhecimento de possíveis lacunas, deficiências interpretativas, aspectos obscuros e temas não discutidos na comunidade, seja pela crença de que não é necessário discuti-los por estarem prontos e acabados, seja pelo respeito àqueles que realizaram, pela primeira vez, determinada atividade.

Nesse sentido, Santos (1997, p. 115) afirma que "no caso de um diálogo intercultural, a troca não é apenas entre diferentes saberes mas também entre diferentes culturas, ou seja, entre universos de sentido diferentes e, em grande maioria, incomensuráveis".

A visão da população tradicional sobre a atividade de subida em açaizeiro por criança, ao lado de um contexto legal de proibição de trabalho infantil, revela a existência de dois cenários distintos dentro de uma mesma sociedade. Ou seja, a diversidade cultural esbarra na proibição legal.

Pensar em diálogo intercultural requer a reflexão sobre a própria carga normativa e valorativa dos direitos humanos. Afinal, a cultura manifesta-se como expressão do desenvolvimento de direitos dos indivíduos que gozam de proteção a direitos básicos, a exemplo da vida e da liberdade. Do mesmo modo, conforme analisado acima, proteger a criança contra toda e qualquer forma de violação, respeitando a sua condição de pessoa em desenvolvimento também denota respeito aos seus direitos humanos.

É nesse contexto de extremos, de dialética, que Santos (1997, p. 107) afirma que "a política dos direitos humanos é basicamente uma política cultural. Tanto é assim que poderemos mesmo pensar os direitos humanos como sinal do regresso cultural, e até mesmo do religioso, em finais do século."

É por essa razão que vem sendo bastante criticada a característica de universalidade dos direitos humanos, pois não há como serem tomados como universais se as particularidades e localismo representam situações diametralmente opostas. Como pensar na aplicação de uma fórmula universal de direitos humanos para uma sociedade plural? De fato, não há como conceber uma solução partindo de tal pressuposto. 
Nesse sentido, Santos (1997, 111-112) afirma que

enquanto forem concebidos como direitos humanos universais tenderão a operar como localismo globalizado - uma forma de globalização de cima-para-baixo. [...] A sua abrangência global será obtida à custa da sua legitimidade local. Para poderem operar como forma de cosmopolitismo, como globalização de baixo-para-cima ou contrahegemônica, os direitos humanos têm que ser reconceptualizados como multiculturais. O multiculturalismo, tal como eu o entendo, é pré-condição de uma relação equilibrada e mutualmente potenciadora entre a competência global e a legitimidade local, que constituem os dois atributos de uma política contra-hegemônica de direitos humanos no nosso tempo.

O multiculturalismo defendido pelo autor permite observar as particularidades de determinada sociedade local e, a partir daí, compreender de que forma é possível garantir a observância de direitos básicos daquela comunidade, sem que isso signifique mera repetição de direitos elencados pela cultura hegemônica.

Com o intuito de permitir a transformação da conceituação e da prática dos direitos humanos de um localismo globalizado para um projeto cosmopolita, Santos (1997) elenca algumas premissas de transformação, a saber:

A primeira premissa é a superação do debate sobre universalismo e relativismo cultural. Trata-se de debate intrinsecamente falso, cujos conceitos polares são igualmente prejudiciais para uma concepção emancipatória de direitos humanos.

A segunda premissa da transformação cosmopolita dos direitos humanos é que todas as culturas possuem concepções de dignidade humana, mas nem todas elas a concebem em termos de direitos humanos.

A terceira premissa é que todas as culturas são incompletas e problemáticas nas suas concepções de dignidade humana, decorrente da própria existência de uma pluralidade de culturas.

A quarta premissa é que todas as culturas têm versões diferentes de dignidade humana, algumas mais amplas do que outras, algumas com círculo de reciprocidade mais largo do que outras, algumas mais abertas a outras culturas do que outras.

A quinta premissa é que todas as culturas tendem a distribuir as pessoas e os grupos sociais entre dois princípios competitivos de pertença hierárquica. Um - o princípio da igualdade - opera através de hierarquias entre unidades homogêneas. O outro - o princípio da diferença - opera através da hierarquia entre identidades e diferenças consideradas únicas.

Nota-se que, em regra, é pressuposto para a adoção de multiculturalismo a ideia de respeito à dignidade da pessoa humana, a despeito dos significados díspares que tal instituto possa ter em diversas culturas.

É a partir do exame de cada cultura e sociedade que será possível extrair o conceito de dignidade humana para aquele grupo. Certo é que, nesse desiderato, deverão ser afastado conceitos e pré-conceitos apreendidos em nossa cultura, sob pena de impor ideias pré- 
concebidas para uma população da qual se pretende extrair um significado. Ou seja, deve-se ter verdadeira flexibilidade de consciência para, antes de julgar, analisar o porquê de determinada atividade ser presente em determinada comunidade, o que revela a essencialidade do diálogo intercultural. Nesse sentido:

$\mathrm{Na}$ área dos direitos humanos e da dignidade da pessoa humana, a mobilização de apoio social para as possibilidades e exigências emancipatórias que eles contém só será concretizável na medida em que tais possibilidades e exigências tiverem sido apropriadas e absorvidas pelo contexto cultural local. Apropriação e absorção, neste sentido, não podem ser obtidas através da canibalização cultural. Requerem um diálogo intercultural e uma hermenêutica diatópica. ( $\quad$ SANTOS, 1997, p. 115116)

Ademais, há que se observar a hermenêutica diatópica, que serve para ampliar ao máximo a consciência de incompletude mútua através de um diálogo que se desenrola, por assim dizer, com um pé numa cultura e outra, noutra. Santos (1997) explica que o reconhecimento da incompletude de determinada cultura que permitirá o diálogo intercultural. $\mathrm{E}$, por assim dizer, somente os membros da comunidade é que poderão reconhecer que sua cultura carece de completude.

Para fins de alcançar o objetivo desejado por meio da hermenêutica diatópica, dois imperativos são indispensáveis e devem ser observados pela comunidade, a saber:

O primeiro pode formular-se assim: das diferentes versões de uma data cultura, deve ser escolhida aquela que representa o círculo mais amplo de reciprocidade dentro dessa cultura, a versão que vai mais longe no reconhecimento do outro. (SANTOS, 1997, p. 121)

O segundo imperativo intercultural pode ser enunciado do seguinte modo: uma vez que todas as culturas tendem a distribuir pessoas e grupos de acordo com dois princípios concorrentes de pertença hierárquica e, portanto, com concepções concorrentes de igualdade e diferença, as pessoas e os grupos sociais têm o direito de ser iguais quando a diferença os inferioriza, e o direito a ser diferentes quando a igualdade os descaracteriza. (SANTOS, 1997, p. 122)

Interessante observar, dentro do diálogo intercultural, que

sociedades diferentes têm percepções divergentes sobre o que é certo e errado, belo e feio, justo e injusto. E os indivíduos tendem, naturalmente, a considerar como injustas, imorais ou absurdas as práticas e condutas adotadas por sociedades diferentes das suas, quando se chocam com os valores e tradições da cultura em que foram socializadas. (SARMENTO, 2016, p. 284) 
Além disso, por vezes, pautados na ideia de respeito às diferenças culturais e de não interferência do estado na comunidade, acaba-se justamente por permitir a violação de direitos dos indivíduos que apresentam vulnerabilidade dentro do grupo social. Nesse contexto, Sarmento (2016, p. 288), destaca a existência de "um paradoxo: em nome da proteção de minorias, prejudicam-se exatamente aqueles que são as minorias dentre as minorias".

É nesse contexto que algumas premissas não podem ser ignoradas. A primeira delas é que

\begin{abstract}
as culturas - inclusive as tradicionais - não são estáticas ou homogêneas; mas campos dinâmicos, em que se entrecruzam visões diferentes, muitas vezes em disputa. Em segundo, as pessoas não são apenas membros de uma coletividade cultural. $\mathrm{O}$ pertencimento a qualquer grupo está longe de esgotar a identidade individual. (SARMENTO, 2016, p. 288-289)
\end{abstract}

Dentro desse cenário, ressalta a importância de garantir o respeito a uma premissa ainda mais valorosa que encerra a ideia de que todas as pessoas são dignas e devem ser tratadas com o mesmo respeito e consideração. Isto porque a Constituição Federal não fez nenhuma discriminação quanto a graus de dignidade dentro de determinado grupo.

Como solução "para evitar o etnocentrismo e enriquecer o conteúdo dos direitos, o melhor remédio é o emprego de diálogos interculturais na sua interpretação e aplicação". (SARMENTO, 2016, p. 290)

É certo que há limitações à realização do diálogo intercultural. Em regra, tais situações decorrem das graves assimetrias entre a sociedade envolvente e a comunidade tradicional. Nesse cenário, é necessária uma postura empática dos operadores do direito diante das tradições e cosmovisões das populações tradicionais, sendo necessário, em primeiro lugar, tentar compreender as razões que estão por trás das práticas tidas como violadoras dos direitos humanos, com exercício de alteridade para saber ouvir o outro e tentar se colocar no seu lugar.

Importante também compreender que a dignidade humana e os direitos fundamentais não podem se converter em instrumentos de imposição forçada de modelos aceitos e tidos como corretos pelos grupos culturalmente hegemônicos.

Além disso, dentro do diálogo, é necessário aceitar que, para determinados temas, a proteção dos direitos fundamentais pode ceder espaço para a garantia da diferença cultural com o objetivo de evitar o completo desfazimento de determinado modo de vida tradicional, que poderia acarretar, inclusive, violação à própria identidade do grupo. 
De outro lado, Sarmento (2016, p. 295) frisa que:

\begin{abstract}
Comunidades tradicionais de qualquer natureza não devem ser vistas como enclaves impenetráveis no interior dos Estados, em que os direitos fundamentais não são bemvindos. Porém, é necessário cuidado na definição da forma da intervenção que visa a defender e promover tais direitos.
\end{abstract}

De todo esse arcabouço, é possível compreender que a realização de diálogo intercultural permite que a comunidade analise criticamente a postura de utilização de mão de obra infantil na cadeia produtiva do açaí e consiga, a partir daí, identificar as consequências decorrentes de tal atividade.

De fato, não se espera a eliminação da cultura. Todavia, em face da alta lesividade e do alto grau de perigo que a atividade proporciona, não há como permitir e incentivar que crianças nela e se exponham.

Busca-se, portanto, uma interpretação intermediária, que concilie a reprodução da cultura, pelo ensinamento às crianças do modo de produção familiar, ao mesmo tempo que se assegure a observância dos direitos que lhes são garantidos.

Entende-se que, por meio do diálogo, a população poderá se tornar consciente de que lugar de criança é na escola e que o futuro do indivíduo dependerá de uma boa formação. Saber diferenciar o trabalho infantil de uma aprendizagem tradicional é crucial nesse contexto. A partir do momento que a criança é obrigada a extrair açaí por exigência do mercado para a obtenção de renda revela-se a existência de atividade produtiva que envolve prática ilegal. De outro lado, nada obsta que a atividade seja ensinada, por meio da transmissão cultural, desde que compatível com o desenvolvimento da criança e dentro de uma área de segurança que não a exponha a risco.

Ainda assim, é possível que a comunidade não se satisfaça por meio do diálogo intercultural e do intercâmbio de conhecimento, preferindo manter o status quo.

Nesse cenário de fracasso do diálogo, será necessário recorrer à outros meios para o equacionamento do problema. Identifica-se a possibilidade de utilização da técnica de ponderação de interesses constitucionais, por meio da qual será necessário aferir, de um lado, a importância dos interesses em disputa para a preservação da cultura minoritária, considerandose os seus efeitos sobre a identidade dos seus integrantes. De outro lado, sopesa-se a intensidade da restrição aos direitos fundamentais impostas às pessoas afetadas. A partir dessa 
reflexão, será possível identificar qual dos direitos será mitigado em detrimento do outro.

\section{CONSIDERAÇÕES FINAIS}

Após a abordagem, identificou-se que a atividade de extração do açaí aumentou em face da procura nos mercados nacional e internacional. Assim, a atividade que antes era desenvolvida apenas para a subsistência da família passou a ter contornos econômicos, com alteração da estrutura socioeconômica dos grupamentos responsáveis pelo cultivo e pela extração do fruto.

A referida atividade, no cenário amazônico, é passada de geração em geração e possui traços nitidamente culturais, como expressão da cultura local, aprendizado constante e valorização dentro da comunidade.

Ocorre que, nas pesquisas realizadas pelo Instituto Peabiru e por Marinho, observou-se a utilização de mão de obra infantil na extração do fruto, surgindo o embate entre a expressão cultural e a utilização de mão de obra proibida.

Delinearam-se os contornos do que se caracteriza como trabalho infantil em termos legais dentro da atividade de extração do açaí, com o apontamento dos riscos existentes e o enquadramento da atividade como uma das piores formas de trabalho infantil.

Nesse cenário, buscou-se uma solução para resolver o conflito. A solução encontrada foi a utilização de diálogo intercultural, por meio do qual a comunidade poderá ter acesso à informação e poderá reconhecer a incompletude de sua atividade e assimilar outras ideias. Destaca-se que, até este ponto, a própria comunidade é que será a responsável por compreender o grau de risco a que estão expostas suas crianças e provocar mudanças efetivas nesse cenário.

Como dito ao longo da exposição, não se trata de eliminação da atividade ou da reprodução cultural, ou seja, que as crianças deixem de ter acesso ao bem imaterial conhecimento. Contudo, é imprescindível que esse conhecimento seja transmitido com respeito e a observância aos direitos da criança, com toda a segurança necessária para evitar sua exposição a risco.

Por fim, em caso de insucesso do diálogo intercultural como instrumento de equacionamento, será necessário recorrer a outros instrumentos, a exemplo da técnica de ponderação de interesses constitucionais. 
Otávio Bruno da Silva Ferreira \& Suzy Elizabeth Cavalcante Koury

Espera-se que o presente estudo contribua para a discussão da temática e que as comunidades se tornem conscientes, de forma mais breve possível, do alto grau de insegurança da atividade e das consequências de utilização do trabalho infantil para que, juntos, possam encontrar outro caminho, seguro e adequado ao desenvolvimento de suas crianças.

\section{REFERÊNCIAS}

BRASIL. Constituição (1988). Constituição da República Federativa do Brasil. Disponível em <http://www.planalto.gov.br/ccivil_03/constituicao/constituicaocompilado.htm> Acesso em 19 jul. 2018.

. Decreto no . 6.481, de 12 de junho de 2008. Regulamenta os artigos $3^{\circ}$, alínea "d", e $4^{\circ}$ da Convenção 182 da Organização Internacional do Trabalho (OIT). Brasília-DF, junho de 2008. Disponível em <http://www.planalto.gov.br/CCiVil_03/_Ato20072010/2008/Decreto/D6481.htm> Acesso em 28 ago. 2018.

Decreto no. 3.597. Promulga Convenção 182 e a Recomendação 190 da Organização Internacional do Trabalho (OIT) sobre a Proibição das Piores Formas de Trabalho Infantil e a Ação Imediata para sua Eliminação, concluídas em Genebra, em 17 de junho de 1999. Disponível em <http://www.planalto.gov.br/ccivil_03/decreto/d3597.htm> Acesso em 19 jul. 2018.

IBGE. Censo Demográfico 2010. Disponível em <https://cidades.ibge.gov.br/brasil/pa/sao-sebastiao-da-boa-vista/panorama> Acesso em 9 jul. 2018.

INSTITUTO PEABIRU. “O Peconheiro": Diagnóstico das condições de trabalho do extrativista de açaí. Belém, Instituto Peabiru, 2016.

MARINHO, José Antônio Magalhães. Dinâmica das relações socioeconômicas e ecológicas no extrativismo do açaí: o caso do médio rio pracuúba, São Sebastião da Boa Vista, Marajó (PA). Belém, 2005. Dissertação de mestrado $186 f$.

ORGANIZAÇÃO INTERNACIONAL DO TRABALHO (OIT). Convenção no. 182. Dispõe sobre a Proibição das Piores Formas de Trabalho Infantil e a Ação Imediata para a sua Eliminação. $\quad$ Genebra, $1999 . \quad$ Disponível <http://www.planalto.gov.br/ccivil_03/decreto/D3597.htm> Acesso em 28 ago. 2018.

Recomendação no. 190 - Dispõe sobre a Proibição das Piores Formas de Trabalho Infantil e a Ação Imediata para a sua Eliminação. Genebra, 1999. Disponível em <http://www.planalto.gov.br/ccivil_03/decreto/D3597.htm> Acesso em 28 ago. 2018. 
POTIGUAR, Manoel; OLIVEIRA, Hermógenes Sá de. Planejamento estratégico para o fortalecimento do arranjo produtivo local da cadeia de valor do açaí do Marajó: uma construção coletiva e territorial. Belém, Instituto Peabiru, 2016.

SANTOS, Boaventura de Souza. Uma concepção multicultural de direitos humanos. Lua Nova [online]. 1997, n.39, pp.105-124. Disponível em: <http://www.scielo.br/pdf/ln/n39/a07n39.pdf> Acesso em 17 jul. 2018.

SARMENTO, Daniel. Dignidade da pessoa humana: conteúdo, trajetórias e metodologia. Belo Horizonte: Fórum, 2016. 